\title{
ESTUDO COMPARADO DE ORGANIZAÇÃO E ADENSAMENTO DE CADEIAS PRODUTIVAS E SEUS INDICADORES: UMA ANÁLISE DAS CÂMARAS SETORIAIS ENTRE 1991, 2006 E 2017
}

\author{
Maicon Gonçalves Monteiro² \\ Helinton José Rocha ${ }^{3}$ \\ Marlon Vinícius Brisola ${ }^{4}$
}

\section{INTRODUÇÃO}

O agronegócio pode ser entendido como a combinação de todas as operaçôes de produção e distribuição de suprimentos agrícolas; das operações de produção nas unidades agrícolas ou agroindústrias; e de armazenamento, processamento e distribuição dos produtos agrícolas e itens ou subprodutos oriundos deles (Davis e Goldberg, 1957). No Brasil, o agronegócio é considerado um dos principais setores que impulsionam a economia do país, transformando-se de forma significativa nas últimas décadas.

A multiplicidade de cadeias produtivas organizadas e competitivas caracteriza a agropecuária brasileira quando comparada a outros países tropicais. Nas últimas três décadas, muitas delas passaram por mudanças significativas na escala e no seu grau de adensamento e complexidade, principalmente devido ao aumento da produtividade, da sustentabilidade e das demandas internacionais (Jank, Zerbini e Cleaver, 2018).

É importante destacar que o desempenho do agronegócio brasileiro sempre teve uma ligação com as açôes do Estado no que tange ao provimento de recursos financeiros e à condução de políticas públicas voltadas ao setor (Fiep, 2016). Dessa forma, quando o Estado muda a maneira de atuar, modificações na organização do agronegócio também passam a ser necessárias.

1. DOI: http://dx.doi.org/10.38116/brua24art18

2. Pesquisador do Núcleo de Estudos de Economia Agrícola (NE²AGRO) na Diretoria de Estudos e Políticas Regionais, Urbanas e Ambientais (Dirur) do Ipea; e mestrando no Programa de Pós-Graduação em Agronegócios da Universidade de Brasília (Propaga/UnB).E-mail: <maicongoncalves675@gmail.com>.

3. Coordenador-geral de apoio às câmaras setoriais e temáticas no Departamento de Estudos e Prospecção da Secretaria de Política Agrícola do Ministério de Agricultura, Pecuária e Abastecimento (Mapa).E-mail:<helinton.rocha@agricultura.gov.br>. 4. Doutor; e professor no Propaga/UnB.E-mail:<mvbrisola@gmail.com>. 
Nessa perspectiva, Júnior et al. (2009, p. 185) destacam que "a abundância de recursos naturais, clima favorável e a evolução biotecnológica e da tecnologia mecânica sempre foram fatores-chave para o seu bom desenvolvimento". Igualmente, o compartilhamento de benefícios, a organização e a disponibilidade de informaçôes de mercado por meio de tecnologias organizacionais para a tomada de decisão dos agricultores e a condução harmônica dos interesses entre os diferentes agentes das várias cadeias produtivas existentes passaram a ser cada vez mais importantes.

Nesse contexto, as câmaras setoriais do Mapa surgem como importantes fóruns de discussão adequados à busca de soluçôes ao desenvolvimento setorial e dos diversos agentes das cadeias produtivas (Brasil, 2019).

As câmaras tiveram sua origem na coordenação de instrumentos fundamentais de política agrícola nacional que, por si, explicam a causa de seus sucessos em diversas cadeias produtivas. Entre esses instrumentos, destacamos a pesquisa agropecuária, a assistência técnica, o cooperativismo, a conformidade dos insumos agropecuários, o crédito rural e tantos outros estabelecidos a partir da Lei Agrícola (Lei no 8.171, de 17 de janeiro de 1991) "como uma primeira tentativa de se estabelecer uma legislação de política agrícola no país" (Takagi, 2000, p. 14). Juntamente com as câmaras setoriais, criava-se o Conselho Nacional de Política Agrícola.

No texto básico da Lei Agrícola, o art. 3 (objetivos) e o art. 4º (açóes e instrumentos) ilustram que o conselho deve equacionar os fatores de sustentabilidade que afetam a produtividade dos sistemas de produção, a estabilidade de seus fatores e a distribuição dos benefícios das cadeias de valores do agronegócio (Brasil, 1991).

$\mathrm{Na}$ ocasiāo em que as câmaras foram criadas, tratava-se de um período no qual a participação direta do Estado nas atividades produtivas encontrava-se em exaustão, e as açôes do setor privado deveriam reverter-se a um entendimento junto ao Executivo governamental (Júnior et al., 2009). Portanto, assim como corrobora Takagi (2000), tais câmaras setoriais surgem num ímpeto de proporcionar um entendimento das necessidades dos diversos setores agrícolas, de forma independente, com o setor público gerador de políticas públicas.

O Brasil é detentor de uma cultura e uma história econômica que valorizaram e priorizaram produtos oriundos de cadeias produtivas específicas do agronegócio, desenvolvendo, portanto, umas mais que outras, tais como as cadeias do algodáo e de aves e suínos, que têm o seu desenvolvimento mais acentuado que as da cachaça, de fibras naturais e de ovinos e caprinos (Brasil, 2019).

Tal realidade, contudo, também depende do nível de organização de cada cadeia produtiva, uma vez que muitas dessas cadeias se mostram fragilizadas pela insuficiência de assistência técnica, pela insustentabilidade econômica da indústria de processamento, pela evasão fiscal em grande parte dos processos e pela falta de inovação tecnológica, entre outros fatores que impactam o nível de informalidade na comercialização, na produçáo e no grau de envolvimento com a exportação (Freitas, Neto e Scalco, 2014; Santos et al., 2019; Schmidt e Silva, 2018; Teixeira et al., 2018).

Diante desse contexto, se faz oportuno realizar uma pesquisa que busque levantar os sucessos e insucessos decorrentes do trabalho das cinco cadeias produtivas citadas (algodão; aves e suínos; cachaça; fibras naturais; e ovinos e caprinos) nas últimas décadas e fazer uma 
análise comparativa entre elas, visando, sobretudo, destacar a eficiência e a eficácia das ações do Estado em suas demandas específicas.

Isso possibilitará a indicação dos desafios a serem enfrentados e as estratégias a serem adotadas nos próximos anos pelos interessados no setor, bem como quais políticas públicas devem ser priorizadas pelos governos e qual o grau de envolvimento dessas políticas nos demais setores do agronegócio.

\section{OBJETIVO GERAL}

Como imperativo, o estudo busca atender a essa inter-relação contextual e, por meio de uma análise comparada entre cadeias mais desenvolvidas e menos desenvolvidas do agronegócio, orientar a pesquisa pelo seguinte objetivo geral.

- Comparar os principais indicadores de desempenho ${ }^{5}$ das cadeias de cachaça, fibras naturais e ovinos e caprinos com os indicadores das cadeias de algodão e aves e suínos, com o intuito de identificar a eficácia das políticas públicas decorrentes das demandas e estratégias estabelecidas nas câmaras setoriais e temáticas do Mapa que afetaram o desempenho do setor entre 1991, 2006 e 2017.

\section{OBJETIVOS ESPECÍFICOS}

- Levantar, em documentos públicos e privados, assim como informaçôes dos censos de 1991, 2006 e 2017, o nível de informalidade na comercialização e produção, além do nível de exportação e organização da cadeia, de forma que se revelem as características e a evolução das cadeias de cachaça, fibras naturais, ovinos e caprinos, algodão e aves e suínos entre 1991, 2006 e 2017.

- Identificar, ao longo do período de tempo em análise, as principais demandas das câmaras setoriais e temáticas aderentes ao setor das cinco cadeias em questão e as principais políticas públicas e ações privadas decorrentes.

- Comparar os efeitos das demandas e políticas nos diferentes períodos analisados, extraindo seus impactos.

\section{RESULTADOS ESPERADOS}

Assim, os resultados esperados permeiam a oferta de um aprendizado sistematizado, mediante a análise de indicadores de desempenho, possibilitando a replicação às demais cadeias produtivas das câmaras setoriais do Mapa, bem como o compartilhamento com outras entidades públicas e privadas de interesse.

Dessa maneira, esta pesquisa permitirá o melhor entendimento da evoluçáo e do desenvolvimento das cadeias produtivas de cachaça, fibras naturais, ovinos e caprinos, algodão e aves e suínos desde o surgimento das câmaras setoriais. Além disso, nos possibilitará conhecer os pontos fortes e fracos de cada uma, as suas respectivas peculiaridades e as similaridades existentes, de forma que se favoreça a produção de políticas públicas e estratégias público-privadas derivadas ao setor. Tais produtos permitirão que essas cadeias se tornem mais competitivas e que sirvam de suporte para que não enfrentem ou mergulhem em crises.

Como resultados dos objetivos do estudo, serão realizados relatórios parcial e final. Será previsto, ainda, um seminário, em que seráo expostos os resultados em data e condiçóes a serem acordadas com o Ipea e o Mapa.

5. Indicadores de desempenho são elementos que podem ser entendidos como uma métrica usada para a mensuração da eficiência ou da eficácia de práticas ou ações especificas (Callado, Callado e Machado, 2007). 


\section{REFERÊNCIAS}

BRASIL. Lei Agrícola no 8171, de 17 de janeiro de 1991. Dispõe sobre a política agrícola. Diário Oficial da Uniấo, Brasília, 18 jan. 1991. Disponível em: <https://bit.ly/3ezudn8>. Acesso em: 16 jan. 2019.

Ministério da Agricultura, Pecuária e Abastecimento. Câmaras setoriais. Brasília: Mapa, 2019. Disponível em: <https://bit.ly/3vRQtOO>. Acesso em: 20 fev. 2020.

CALLADO, A. A. C.; CALLADO, A. L. C.; MACHADO, M. A. V. Indicadores de desempenho operacional e econômico: um estudo exploratório no contexto do agronegócio. Revista de Negócios, v. 12, n. 1, p. 3-15, 2007.

DAVIS, J. A.; GOLDBERG, R. A. A concept of agribusiness. Boston: Harvard University Graduate School of Business Administration, 1957. p. 4-24.

FREITAS, T. R.; NETO, R. S.; SCALCO, P. R. Cadeias produtivas do agronegócio de Goiás. Goiânia: UFG, 2014. (Textos para Discussão, n. 40).

FIEP - FEDERAÇÃO DAS INDÚSTRIAS DO ESTADO DO PARANÁ. Desenvolvimento das cadeias produtivas: fortalecimento das cadeias produtivas. Fiepr.org, 2016. Disponível em: $<$ https://bit.ly/3o9djPa>. Acesso em: 20 fev. 2020.

JANK. M. S.; ZERBINI, A. N.; CLEAVER, I. Competitividade internacional do agronegócio brasileiro, visão estratégica e políticas públicas. In: RODRIGUES, R. (Org.). Agro é paz: análises e propostas para o Brasil alimentar o mundo. Piracicaba: Esalq, 2018.

JÚNIOR, C. A. G. et al. Um estudo das deliberaçóes da Câmara Setorial do Açúcar e do Álcool, usando análise de correspondência. Revista de Economia e Sociologia Rural, v. 47, n. 1, p. 183-210, 2009.

SANTOS, L. G. et al. Central de cooperativas na comercialização de produtos da agricultura familiar: o caso da Centrafes do estado de Sergipe, Brasil. Otra Economía, v. 12, n. 22, p. 22-41, 2019.

SCHMIDT, N. S.; SILVA, C. L. Pesquisa e desenvolvimento na cadeia produtiva de frangos de corte no Brasil. Revista de Economia e Sociologia Rural, v. 56, n. 3, p. 467-482, 2018.

TAKAGI, M. Câmaras setoriais agroindustriais, representaçáo de interesses e políticas públicas. 2000. Dissertação (Mestrado) - Universidade Estadual de Campinas, Campinas, 2000.

TEIXEIRA, F. O. et al. Crescimento econômico dos estados brasileiros através da sofisticação de suas exportaçôes agropecuárias (2002-2014). Revista de Desenvolvimento Econômico, v. 1, n. 39, 2018. 